\title{
A Computational Study of Silicon and Germanium- Based Molecules in Terms of Solar Cells Performance
}

Emine Tanış ( $\nabla$ eminetanis@ahievran.edu.tr)

Ahi Evran Universitesi https://orcid.org/0000-0001-6815-9286

\section{Research Article}

Keywords: Reorganization energy, charge transfer rate, transfer integral, DFT

Posted Date: February 24th, 2021

DOl: https://doi.org/10.21203/rs.3.rs-227858/v1

License: (c) (1) This work is licensed under a Creative Commons Attribution 4.0 International License.

Read Full License 


\title{
A computational study of silicon and germanium-based molecules in terms of solar cells performance
}

\section{Emine Tanış}

Department of Electrical Electronics Engineering, Faculty of Engineering and Architecture Kırşehir Ahi Evran University, Kırsehir, Turkey

eminetanis@ahievran.edu.tr

\begin{abstract}
Photovoltaic energy sources are increasingly in demand due to concerns over the cost of petroleum fuels and carbon emissions. Silicon based photovoltaic production is relatively high. Silicon and germanium-based semiconductors with 1,1,2,3,4,5-Hexaphenyl-1H-silole (HPS) and 1,1,2,3,4,5-Hexaphenyl-1H-germole (HPG) 's to determine the appropriateness in terms of photovoltaic applications, electronic structure and charge transport properties density functional theory (DFT) and by Marcus theory have been investigated. Absorption spectra, reorganization energies $\left(\lambda_{\mathrm{e}}\right.$ and $\left.\lambda_{\mathrm{h}}\right)$, frontier orbitals, the ionization potentials (IPs) and the electron affinities (EAs), the effective transfer integrals $\left(V_{e}\right.$ and $\left.V_{h}\right)$, and the charge transfer rates $\left(\mathrm{W}_{\mathrm{e}}\right.$ and $\left.\mathrm{W}_{\mathrm{h}}\right)$ were determined. HPG can be said to have better photovoltaic properties with high electron transfer rate, narrow band gap and low excitation energy. In addition, we can say that HPS is a suitable candidate for hole injection layer with its high hole transfer properties. Accordingly, these molecules are potential candidates for the manufacture of photovoltaic solar cells and optoelectronic devices.
\end{abstract}

Keywords: Reorganization energy, charge transfer rate, transfer integral, DFT

\section{Introduction}

In recent years, due to the increasing energy requirement, solar cells have become a very popular energy source. This energy obtained by using photovoltaic technology is obtained by converting solar energy into electrical energy. They are accepted as a solution for increasing energy consumption thanks to their low cost and nature-friendly nature $[1,2]$. In the literature, there are studies on the reaction chemistry of many molecules containing silocon and germole [3-7]. Silicon-based solar cells, which are considered inorganic, are candidate materials used to 
increase the performance of heterojunction devices [8,9]. Despite its many disadvantages, the most used photovoltaic technology is silicon solar cells [10]. Similarly, some germanium-based compounds have been found to be suitable molecules for photovoltaic devices and plastic electronics with photophysical properties [11-15]. In a study conducted in 2007, the photoluminescence character of HPS and HPG was determined by various experimental measurements [7]. However, in our knowledge, there is no study in the literature regarding the charge transfer characteristics of HPS and HPG and their performance in photovoltaic solar cells.

DFT (TD-DFT) calculations are extensively used in order to improve optoelectronic and materials photovoltaic properties of photovoltaic [16,17]. Such theoretical studies are important to save time and money and to optimize their experimental procedures.

In this report, the photovoltaic, electronic and transporting properties for HPS and HPG semiconductor samples are explored by density functional theory (DFT) and Marcus theory calculations.

\section{METHODS}

All the calculations of the studied molecules were performed using the Gaussian 09 [18] and Amsterdam density functional (ADF2019) [19] programs. Electronic and photovoltaic calculations of optimized molecules using the B3LYP function with $6-311++G(d, p)$ basis set were also performed on the same basis set.

ADF is a successful computational chemistry software for calculating molecules in terms of structure, electronics, optics and more. Firstly, the dimer structures of mentioned compounds were optimized in the ADF program. Next, the charge transfer integrals of HPS and HPG molecules optimized at the B3LYP/TZP level were calculated.

Charge transfer rate (W) of HPS and HPG is found by following equation [20-23], known as the Marcus-Hush equation.

$W=\frac{V^{2}}{\hbar}\left(\frac{\pi}{\lambda k_{B} T}\right)^{1 / 2} \exp \left(-\frac{\lambda}{4 k_{B} T}\right)$

Where $\lambda$ is the reorganization energy, $\mathrm{T}$ is the temperature, $\mathrm{V}$ is the effective charge transfer integral and $\hbar$ and $\mathrm{k}_{\mathrm{B}}$ are the Planck and Boltzmann constants, respectively. 
$\mathrm{V}_{\mathrm{ij}}$ representing the electronic coupling between intermolecules; depending on the spatial overlap $\left(\mathrm{S}_{\mathrm{ij}}\right)$, charge transfer integrals $\left(\mathrm{J}_{\mathrm{ij}}\right)$ and site energies $\left(\mathrm{e}_{\mathrm{i}}(\mathrm{j})\right)$, respectively,

$V=\frac{J_{i j}-S_{i j}\left(e_{i}+e_{j}\right) / 2}{1-S_{i j}^{2}}$

The reorganization energy associated with the charge transport process in organic solids can be defined in two ways: The first of these is the normal mode analysis method, which is the method that divides the total relaxation energy by the contributions from each vibration mode. The second is the four-point approach, which is the method we use here, and in this approach, the $\lambda$ can be shown as in equation 3. The total reorganization energy is the sum of the internal reorganization energies created by the intermolecular vibration and the external reorganization energies created by the polarization of the surrounding environment. The external reorganization energy of a few tenths of an electron volt is a very small value [24,25]. Therefore, the internal reorganization energies created by an electron or a hole are taken into account in this paper. Electron (or hole) reorganization energies, $\lambda_{\mathrm{e}}$ (or $\lambda_{\mathrm{h}}$ ) can be written as follows:

$$
\begin{aligned}
\lambda_{h} & =\lambda_{1}+\lambda_{2}=\left[E^{+}\left(g^{0}\right)-E^{+}\left(g^{+}\right)\right]+\left[E^{0}\left(g^{+}\right)-E^{0}\left(g^{0}\right)\right] \\
& =\left[\left(E^{+}\left(g^{0}\right)-E^{0}\left(g^{0}\right)\right]-\left[\left(E^{+}\left(g^{+}\right)-E^{0}\left(M^{+}\right)\right)\right]\right.
\end{aligned}
$$

and

$$
\begin{aligned}
\lambda_{e} & =\lambda_{3}+\lambda_{4} \\
& =\left[E^{0}\left(g^{-}\right)-E^{0}\left(g^{0}\right)\right]+\left[E^{-}\left(g^{0}\right)-E^{-}\left(g^{-}\right)\right] \\
& =\left[E^{0}\left(g^{-}\right)-E^{-}\left(g^{-}\right)\right]-\left[E^{0}\left(g^{0}\right)-E^{-}\left(g^{0}\right)\right]
\end{aligned}
$$

$\mathrm{E}^{0}\left(\mathrm{~g}^{0}\right)$ is the energy of the neutral molecule in neutral geometry, $\mathrm{E}^{+/-}\left(\mathrm{g}^{+/-}\right)$is ion energy (cation/anion) in ionic geometry, $\mathrm{E}^{+/-}\left(\mathrm{g}^{0}\right)$ is ion energy (cation/anion) in neutral geometry, and $\mathrm{E}^{0}\left(\mathrm{~g}^{+/-}\right)$in ionic geometry, the energies of the neutral molecule are shown in equations 3 and 4. The injection processes of holes and electrons, which affect the performance of the devices, are highly dependent on their stability and energy barriers [26]. There are many studies in literature on the injection ability of molecules using HOMO, LUMO, ionization potentials $\left(\mathrm{IP}_{\mathrm{a}} / \mathrm{IP}_{\mathrm{v}}\right)$ and electron affinities $\left(\mathrm{EA}_{\mathrm{a}} / \mathrm{Ea}_{\mathrm{v}}\right)$.

There are many studies in literature about the injection ability of molecules depending on HOMOs, LUMOs, ionization potentials (IPa/IP $\left.{ }_{v}\right)$ and electron affinities (EAa/Eav) [27-30]. 
The vertical and adiabatic ionization potentials $\left(\operatorname{IP}_{\mathrm{v}} / \mathrm{IP}_{\mathrm{a}}\right)$, the vertical and adiabatic electron affinities $\left(\mathrm{Ea}_{v} / \mathrm{EA}_{\mathrm{a}}\right)$ of the studied structures were obtained as follows:

$$
\begin{aligned}
& I P(v)=E^{+}\left(g^{0}\right)-E^{0}\left(g^{0}\right) \\
& I P(a)=E^{+}\left(g^{+}\right)-E^{0}\left(g^{0}\right) \\
& E A(v)=E^{0}\left(g^{0}\right)-E^{-}\left(g^{0}\right) \\
& E A(a)=E^{0}\left(g^{0}\right)-E^{-}\left(g^{-}\right)
\end{aligned}
$$

\section{RESULTS AND DISCUSSION}

\subsection{Geometric structures and electronic properties}

Optimized monomer structures of HPS and HPG molecules using DFT method are portrayed in Figure 1. The energy of the HPS molecule was calculated as -1832.21106368 a.u and the energy of the HPG molecule as -3619.68363740 a.u. This result shows that the HPG molecule is more stable than HPS.

The electron donating and receiving orbitals of a molecule, also called frontier molecular orbitals, the HOMO, LUMO orbitals, and the difference between these orbitals are important in terms of charge transfer. Figure 2 shows the contour plots of the HOMO and LUMO molecular orbitals of the studied molecules. The energy of donor HOMO orbitals were calculated as $-9.20 \mathrm{eV}$ for HPG and $-8.83 \mathrm{eV}$ for HPS. Therefore, HPS is a higher molecule in terms of hole-creating potential [31]. The energy of acceptor LUMO orbital (-6.18 eV) of HPS is higher than HPG $(-6.62 \mathrm{eV})$. This indicates that HPS has a high ability to receive electrons.

The electrochemical bandgap, which is the energy difference between HOMO and LUMO levels, and the optical band gap, which is the excitation energy for transitions between vertical bands, are different energies [32]. Here, the $2.58 \mathrm{eV}$ and $2.65 \mathrm{eV}$ energy values calculated using the TD-DFT method show the electrochemical bandgaps of HPG and HPS, respectively, and the energy values of $3.59 \mathrm{eV}$ and $3.58 \mathrm{eV}$ show the optical band gaps of HPG and HPS, respectively. The small energy difference between the electrochemical bandgap and the optical band gap means that the charge transfer rate is large [33]. The small energy difference between the electrochemical bandgap and the optical band gap means that the charge transfer rate is large. This difference is $0.91 \mathrm{eV}$ for HPS and $1.01 \mathrm{eV}$ for HGS. From this result, it can be said that HPG is a material with a higher charge transfer rate. In addition, since the electrochemical band gap of HPS is higher than that of HPG, it absorbs less sunlight. 


\subsection{Reorganizational energy}

The calculated reorganization energies, adiabatic/vertical ionization potentials and adiabatic and vertical electron affinities of HPS and HPG molecules are tabulated in Table 1. These calculated values are factors affecting the performance of solar cells. For example, the mobility of electrons and holes is closely related to the reorganizational energy.

The greater the reorganization energy of an electron or hole, the smaller its transport rate. It can be seen from Table 1 that the $\lambda_{\text {hole }}$ of both the HPS and the HPG molecule is smaller than the $\lambda$ electron. In other words, it is seen from the results in Table 1 that HPG can be used as electron transport material and HPS can be used as hole transport material in terms of its use in future solar cells.

The way to understand the charge transfer barrier using computational chemistry methods is to calculate ionization potentials (IPs) and electron affinities (EA's). Magnitudes such as electron affinity (EA) and ionization potential significantly affect the energy threshold available for the injection of holes and electrons in a molecule. The bigger EA and smaller IP means better electron and hole transport [34]. Table 1 shows all adiabatic/vertical EAa/v and $\mathrm{IP}_{\mathrm{a} / \mathrm{v}}$ values of HPS and HPG molecules. The $\mathrm{EA}_{\mathrm{a} / \mathrm{v}}$ and IP $\mathrm{I}_{\mathrm{a} / \mathrm{v}}$ values of HGS 2.231/1.986 eV and 5.687/5.959, respectively. Similarly, the $\mathrm{EA}_{\mathrm{a} / \mathrm{v}}$ and $\mathrm{IP}_{\mathrm{a} / \mathrm{v}}$ values of HPS $0.816 / 0.544 \mathrm{eV}$ and 6.639/6.884, respectively. Therefore, the HPG molecule can form suitable for the electron injection layer and the HPS molecule for the hole injection layer.

\subsection{Dipole moment}

Another factor that affects the performance of solar cells is the dipole moment. Dipole moment plays an important role in the production of solar cells as it affects the solubility of a molecule in any solvent. A molecule with a dipole moment in chloroform, an organic solvent, is known to have high solubility. For this reason, dipole moments of the studied molecules were calculated by using B3LYP/6-311G (d, p) basis set in chloroform solvent. As can be seen from Table 1, it is seen that HPG has a larger dipole than HPS. Therefore, the HPG molecule can grow more by itself in the chloroform solvent, which makes it easier for charge transfer. As can be seen from Table 1, it is seen that HPG has a larger dipole than HPS. Therefore, the HPG molecule can self- assembly in the chloroform solvent and grow more, which indicates that the charge transfer is greater in HPS.

\subsection{Effective transfer integrals and charge transfer rates}


The effective transfer integrals $\mathrm{V}$ represent the strength of the electronic coupling between two neighboring molecules $i$ and $j$ and may vary depending on the geometry of the dimer. In addition, the charge transfer must be anisotropic. [22,23,35,36]. To create this anisotropic geometry at a reasonable level, the molecules that make up the dimer were thought in parallel. Because the interactions between $\pi$-conjugated coupling that facilitate charge transport between neighboring compounds are strong interactions. Optimized dimer structures obtained by using parallel dimer geometry for HPG and HPS are given in Figure 3 and transfer integrals belonging to these geometries are given in Table 2. It is known that the larger the transfer integral, the greater the charge transfer. It can be seen from Table 2 that HPG has higher electron transfer integral (absolute) than HPS. Also, the hole transfer integral of HPS is much higher than HPG. Thus, it can be said that HPS is a good candidate as hole transfer material.

Charge transfer rates ( $\mathrm{W}_{\text {electron }}$ and $\mathrm{W}_{\text {hole }}$ ) are calculated using equation 1 for HPS and HPG in parallel geometry at $298.15 \mathrm{~K}$ and are tabulated in Table 2. HPG molecule has a high electron transfer rate $\left(530 \times 10^{9} \mathrm{~s}^{-1}\right)$. On the other hand, the HPS molecule has a large hole transfer rate $\left(140 \times 10^{9} \mathrm{~s}^{-1}\right)$.

\subsection{Optical properties}

The maximum peak of absorption spectra, oscillation strength (f), excitation energy $(\Delta \mathrm{E})$ and major contributions of the studied molecules in chloroform solvent calculated at the level of TD-DFT/B3LYP/6-311G(d,p) are tabulated in Table 3. The HPG molecule exhibits absorbance spectra in the range of 354-266 nm, and the HPS molecule exhibits absorption spectra in the range of 346-266 $\mathrm{nm}$. From these results, HPG revealed the highest $\lambda_{\max }(354 \mathrm{~nm})$ with narrow energy gap $(2.58 \mathrm{eV})$. This suggests that this molecule (HPG) is an excellent candidate for efficient solar cells with better optical and electronic properties. Also, the performance of solar cells is related to excitation energy. In general, it has been observed that a molecule with low excitation energy always has a high charge transfer [37,38]. In addition, it can be said that the lower excitation energy of a molecule has better photovoltaic properties. In this sense, it is seen from Table 3 that the HPG molecule has higher charge transfer and better photovoltaic properties than HPS with low excitation energy of $3.59 \mathrm{eV}$ during the transition between HOMO-LUMO orbitals.

\section{Conclusion}

In the present study, advance quantum theoretical calculations have been used to examine the charge transfer properties, photovoltaic and electronic properties of HPS and HPG molecules. 
The reorganization energies and Marcus-Hush theory proved that HPG can be used as electron transport material and HPS can be used as hole transport material. In addition, it has been determined that HPG is a perfect candidate for a solar cell in terms of absorbance spectra, electrochemical, optical band gaps and photovoltaic properties.

\section{References}

1. Agrawal, M., Photonic design for efficient solid-state energy conversion. Ph.D. thesis., Stanford University (2009)

2. Thauer, R. K. A fifth pathway of carbon fixation, Science. 318, 5857 (2007)

3. Dubac, J., Laporterie A., and Manuel, G. Group 14 metalloles. 1. Synthesis, organic chemistry, and physicochemical data, Chem. Rev. 90, 215 (1990)

4. Colomer, E., R. Corriu, J. P., and Lheureux, Group 14 metalloles. 2. Ionic species and coordination compounds, M., Chem. Rev. 90, 265 (1990)

5. Saito, M., and Yoshioka, M., The anions and dianions of group 14 metalloles, Coord. Chem. Rev. 249, 765 (2005)

6. Hennig, H., Heckner, K.H., Pavlov, A.A., and Kuzmin, M.G., Spectroscopic properties of silacyclopentadiede derivatives, Ber. Bunsen-Ges. Phys. Chem. 84, 1122 (1980)

7. Mullin J.L., Tracy J.H., Ford J.R., Keenan S.R., Keenan S.R. and Fridman F., Characteristics of Aggregation Induced Emission in 1,1-Dimethyl-2,3,4,5-tetraphenyl and 1,1,2,3,4,5-Hexaphenyl Siloles and Germoles, J. Inorg Organomet Polym. 17,1 (2007)

8. Li, J.Y., Hung, C.H., Chen, C.Y., Hybrid black silicon solar cells textured with the interplay of copper-induced galvanic displacement, Sci. Rep. 717177 (2017)

9. Dobrzanski, L., Szindler, M., Drygała, A., Szindler, M., Silicon solar cells with A12O3 antireflection coating, Centr.Eur.J Phys. 12666 (2014).

10. Bagnall, D. M., and Boreland, M., Photovoltaic technologie, En. Pol., 36, 12 (2008)

11. Allard, N., Aich, R.B., Gendron, D., Boudreault, P.L.T. Tessier, C., Alem, S., Tse, S.C., Tao, Y., Leclerc, M., Germafluorenes: New Heterocycles for Plastic Electronics, Macromolecules, 432328 (2010) 
12. Miller, R. D., Sooriyakumaran, R. J. Polym. Sci., Part A: Polym. Chem., Polysilanes: Solution Photochemistry and Deep-UV Lithography, 25, 111 (1987)

13. Yabusaki, Y., Ohshima, N., Kondo, H., Kusamoto, T., Yamanoi, Y., Nishihara, H., Versatile Synthesis of Blue Luminescent Siloles and Germoles and Hydrogen-BondAssisted Color Alteration, Chem. Eur. J., 16, 5581 (2010)

14. Hwang, Y.M., Ohshita, J., Harima, Y., Mizumo, T., Ooyama, Y., Morihara, Y., Izawa, T., Sugioka, T., Fujita, A., Synthesis, characterization, and photovoltaic applications of dithienogermole-dithienylbenzothiadiazole and dithienylthiazolothiazole copolymers, Polymer, 5218 (2011)

15. Amb, C. M., Chen, S., Graham, K. R., Subbiah, J., Small, C. E., So, F., Reynolds, J.R., Dithienogermole As a Fused Electron Donor in Bulk Heterojunction Solar Cells, J. Am. Chem. Soc. 13326 (2011)

16. Wang, Y.L., Li Q.S., and Li Z.S., End-capped group manipulation of fluorene-based small molecule acceptors for efficient organic solar cells., Comp. Mater. Sci. 156252 (2019)

17. Zhang, L., Shen W., He, R., Liu, X., Tang, X., Yang, Y., and Li, M., Fine structural tuning of diketopyrrolopyrrole-cored donor materials for small molecule-fullerene organic solar cells: A theoretical study. Organic Electronics 32134 (2016)

18. Frisch, M.J., Trucks, G.W., Schlegel, H.B., Scuseria, G.E., Robb, M.A., Cheeseman, J.R., Scalmani, G., Barone V., Petersson, G.A., Nakatsuji, H., Li, X., Caricato, M., Marenich, A.V., Bloino, J., Janesko, B.G., Gomperts, R., Mennucci, B., Hratchian, H. P., Ortiz, J.V., Izmaylov, A.F., Sonnenberg, J.L., Williams, F. Ding, F. Lipparini, F. Egidi, J. Goings, B. Peng, A. Petrone, T. Henderson, D. Ranasinghe, V. G. Zakrzewski, J. Gao, N. Rega, G. Zheng, W. Liang, M. Hada, M. Ehara, K. Toyota, R. Fukuda, J. Hasegawa, M. Ishida, T. Nakajima, Y. Honda, O. Kitao, H. Nakai, T. Vreven, K. Throssell, J. A. Montgomery Jr., J. E. Peralta, F. Ogliaro, M. J. Bearpark, J. J. Heyd, E. N. Brothers, K. N. Kudin, V. N. Staroverov, T. A. Keith, R. Kobayashi, J. Normand, K. Raghavachari, A. P. Rendell, J. C. Burant, S. S. Iyengar, J. Tomasi, M. Cossi, J. M. Millam, M. Klene, C. Adamo, R. Cammi, J. W. Ochterski, R. L. Martin, K. Morokuma, O. Farkas, J. B. Foresman, D. Fox, Gaussian 16, Revision C.01, Gaussian, Inc., Wallingford, CT (2016)

19. ADF2019, SCM, Theoretical Chemistry, Vrije Universiteit, Amsterdam, The Netherlands, http://www.scm.com 
20. Wen, S.H., Li A., Song, J.L., Deng, W.Q., Han, K.L., Goddard, W.A., First-Principles Investigation of Anistropic Hole Mobilities in Organic Semiconductors, J. Phys. Chem. B 1138813 (2009)

21. Chai, S., Wen, S. H., Huang, J. D., Han, K.L., Density functional theory study on electron and hole transport properties of organic pentacene derivatives with electronwithdrawing substituent, J. Comput. Chem., 323218 (2011)

22. Deng, W.Q., Sun, L., Huang, J.D., Chai, S., Wen, S.H., Han, K.L., Quantitative prediction of charge mobilities of $\pi$-stacked systems by first-principles simulation Nat. Protoc. 2015, 10, 632.

23. Huang, J. D., Wen, S. H., K. L. Han, First-Principles Investigation of the Electronic and Conducting Properties of Oligothienoacenes and their Derivatives, Chem.-Asian J. 71032 (2012)

24. Yin, S., Yi, Y., Li, Q., Yu, G., Liu, Y. and Shuai, Z., Balanced Carrier Transports of Electrons and Holes in Silole-Based Compounds-A Theoretical Study, J. Phys. Chem. A, 1107138 (2006)

25. McMahon D.P. and Troisi A., Evaluation of the External Reorganization Energy of Polyacenes, J. Phys. Chem. Lett., 1941 (2010)

26. H. Sahu, A.N. Panda, Computational investigation of charge injection and transport properties of a series of thiophene-pyrrole based oligo-azomethines, Phys.Chem.Chem.Phys., 168563 (2014)

27. Y. Wen and Y. Liu, Recent Progress in n-Channel Organic Thin-Film Transistors, Adv. Mater., 2212 (2010)

28. L. Wang, B. Xu, J. Zhang, Y. Dong, S. Wen, H. Zhang and W. Tian, Theoretical investigation of electronic structure and charge transport property of 9,10distyrylanthracene (DSA) derivatives with high solid-state luminescent efficiency, Phys. Chem. Chem. Phys. 715 (2013)

29. García, G., Moral M., Garzón A., Granadino-Roldán J.M., Navarro, A., FernándezGómez M., Poly(arylenethynyl-thienoacenes) as candidates for organic semiconducting materials. A DFT insight, Org Electron, 1312 (2012)

30. Li, Y., Zou, L.Y., Ren, A.M. and Feng, J.K., Theoretical study on the electronic structures and photophysical properties of a series of dithienylbenzothiazole derivatives, Comput. Theor. Chem., 98114 (2012) 
31. Hlel, A., Mabrouk, A., Chemek, M., Khalifa, I.B., Alimi, K., A DFT study of chargetransfer and opto-electronic properties of some new materials involving carbazole units, Computational Condensed Matter, 3 (2015)

32. Reynolds J.R., Thompson B.C. and Skotheim T.A., Conjugated Polymers Properties, Processing and Applications, (CRC Press, Fourth Edition, Newyork) pp. 61 (2019)

33. Javier, P., Enrique, C., Alex, W.C., Javier, A., Susana, F.H., and Martin, B.P., Wavelet analysis of molecular dynamics: Efficient extraction of time-frequency information in ultrafast optical processes, J. Chem. Phys., 13922 (2013)

34. Rohloff, R., Kotadiya, N.B., Craciun, N.I., Blom, Wetzelaer, G.A.H., Electron and hole transport in the organic small molecule $\alpha$-NPD, Appl. Phys. Lett. 110073301 (2017)

35. Wen, S.H., Li, A., Song, J.L., Deng, W.Q., Han, K.L., Goddard, W.A., First-Principles Investigation of Anistropic Hole Mobilities in Organic Semiconductors, J. Phys. Chem. B 11326 (2009)

36. Chai, S., Wen, S.H., Huang, J.D., Han, K.L., Density functional theory study on electron and hole transport properties of organic pentacene derivatives with electronwithdrawing substituent, J. Comput. Chem., 3215 (2011)

37. Mutailipu, M., Xie, Z., Su, X., Zhang, M., Wang, Y., Yang, Z., Janjua, M.R.S.A., Pan, S., Chemical Cosubstitution-Oriented Design of Rare-Earth Borates as Potential Ultraviolet Nonlinear Optical Materials, J. Am. Chem. Soc. 13950 (2017)

38. Janjua, M.R.S.A., Quantum Mechanical Design of Efficient Second-Order Nonlinear Optical Materials Based on Heteroaromatic Imido-Substituted Hexamolybdates: First Theoretical Framework of POM-Based Heterocyclic Aromatic Rings, Inorg. Chem. 51 21 (2012)

\begin{tabular}{|l|l|l|l|l|l|l|l|}
\hline \multicolumn{2}{|l|}{ Table 1. The calculated reorganization energies (in eV). } \\
\hline Molecules & $\lambda_{\text {electron }}$ & $\lambda_{\text {hole }}$ & $\mathbf{I P}_{\mathbf{a}}$ & $\mathbf{I P}_{\mathbf{v}}$ & $\mathbf{E A}_{\mathbf{a}}$ & $\mathbf{E A}_{\mathbf{v}}$ & $\begin{array}{l}\text { Dipol } \\
\text { Moment } \\
\text { (Debye) }\end{array}$ \\
\hline HPS & 0.598 & 0.517 & 6.639 & 6.884 & 0.816 & 0.544 & 0.0184 \\
\hline HPG & 0.326 & 0.244 & 5.687 & 5.959 & 2.231 & 1.986 & 0.1909 \\
\hline
\end{tabular}




\begin{tabular}{|l|l|l|l|l|}
\hline \multicolumn{5}{|l|}{ Table 2. The charge transfer integrals (in eV) and the charge transfer rates (in s ${ }^{-1}$ ). } \\
\hline Molecules & $\mathbf{V}_{\text {electron }}$ & $\mathbf{V}_{\text {hole }}$ & $\mathbf{W}_{\text {electron }}$ & $\mathbf{W}_{\text {hole }}$ \\
\hline HPS & -0.00034 & -0.00207 & $2.6 \times 10^{9}$ & $140 \times 10^{9}$ \\
\hline HPG & 0.00047 & 0.00002 & $530 \times 10^{9}$ & $5 \times 10^{9}$ \\
\hline & & & & \\
\hline
\end{tabular}

Table 3. The computed absorption wavelengths, excitation energies, absorbance and oscillator strengths.

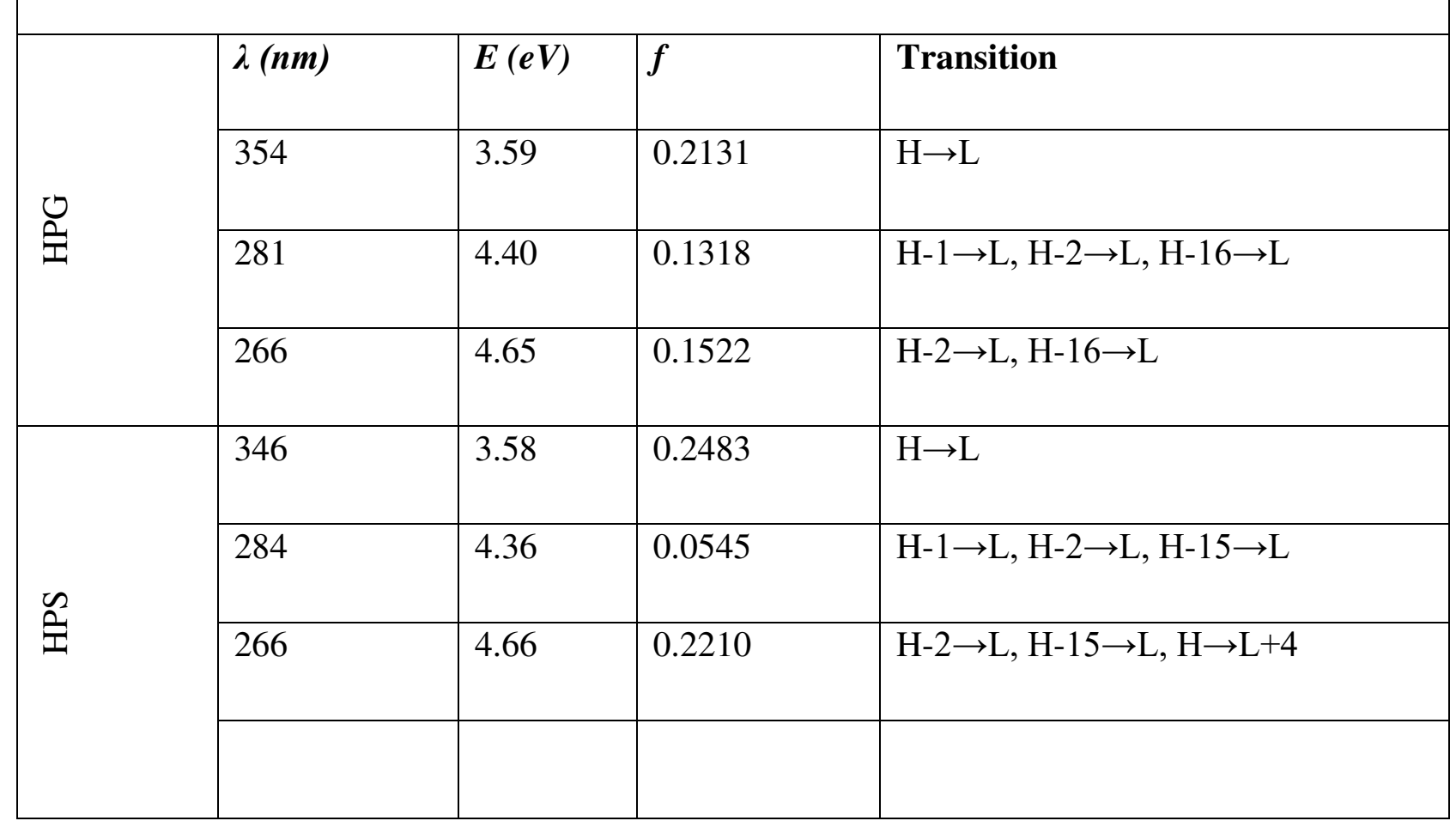


a)

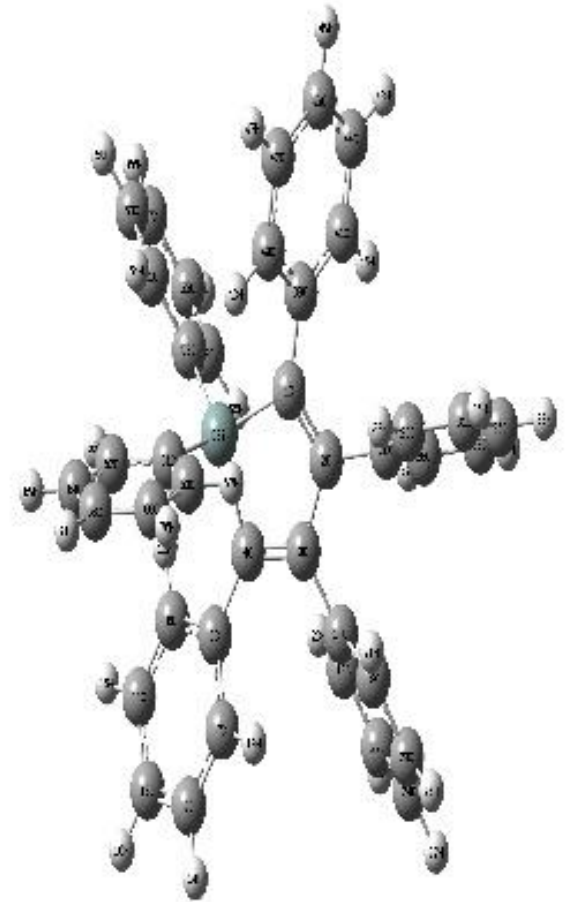

b)

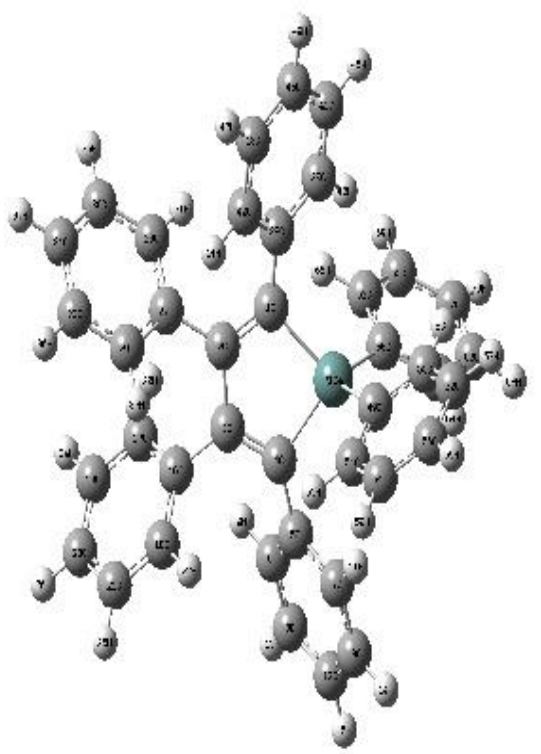

Fig.1. Optimized molecular structures of a)HPS and b)HPG. 
a)
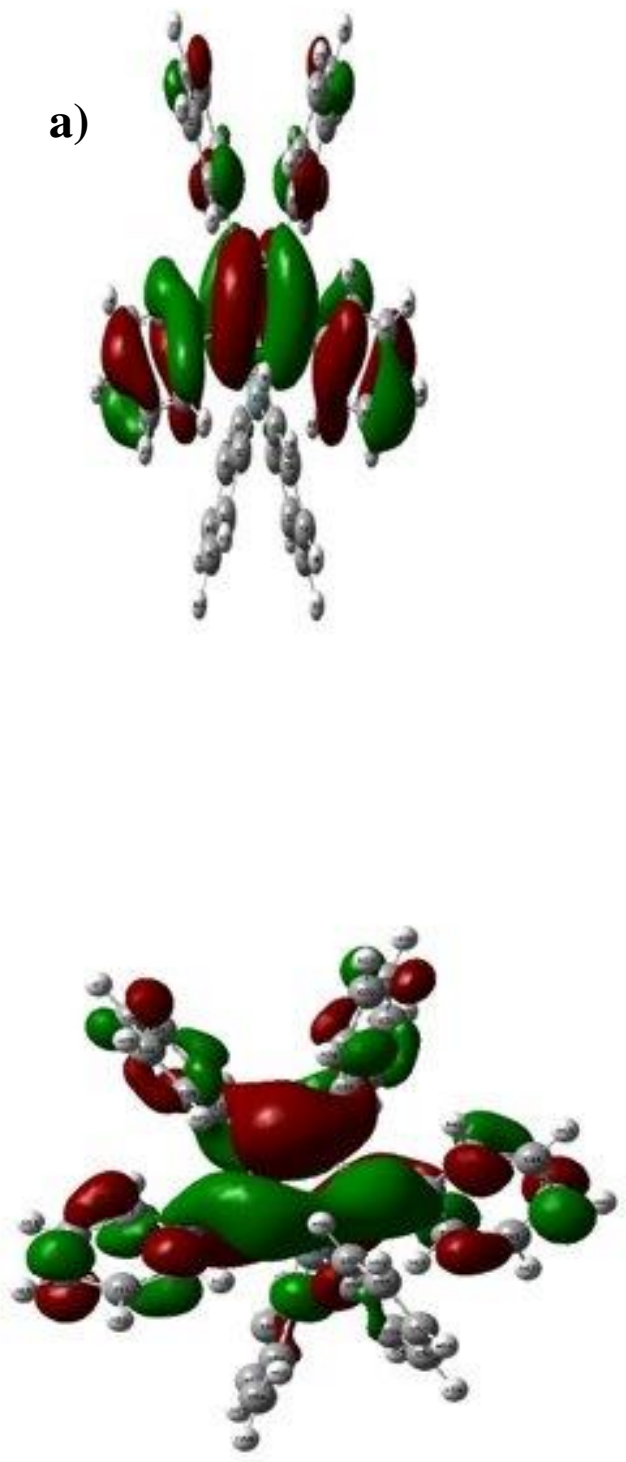

\section{$\mathbf{E}_{\text {номо }}=-8.83 \mathrm{eV}$}
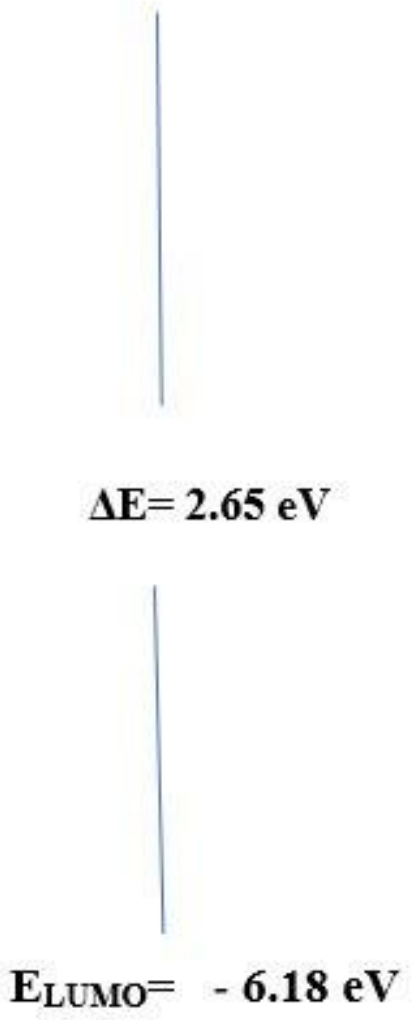
b)
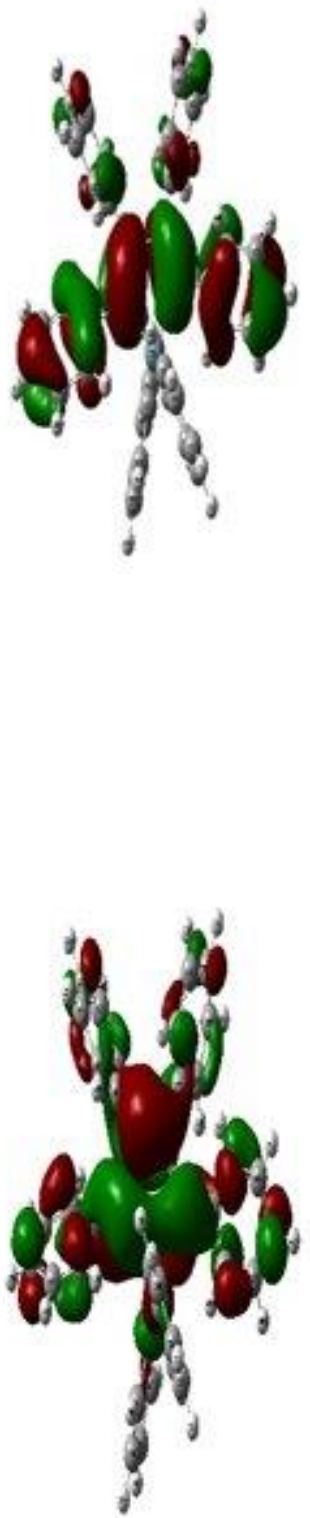

\section{$\mathrm{E}_{\text {Hомо }}=-9.20 \mathrm{eV}$}

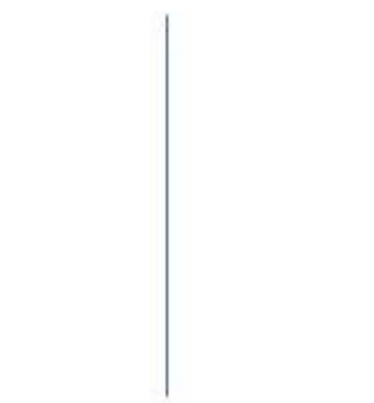

$\Delta \mathbf{E}=\mathbf{2 . 5 8} \mathrm{eV}$

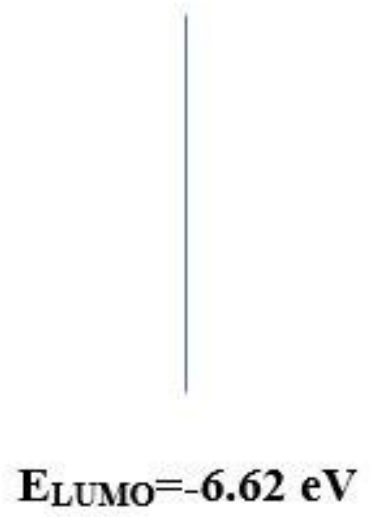

$E_{\text {LUMO }}=-6.62 \mathrm{eV}$

Fig.2. Frontier orbital contour plot a)HPS and b)HPG. 
a)

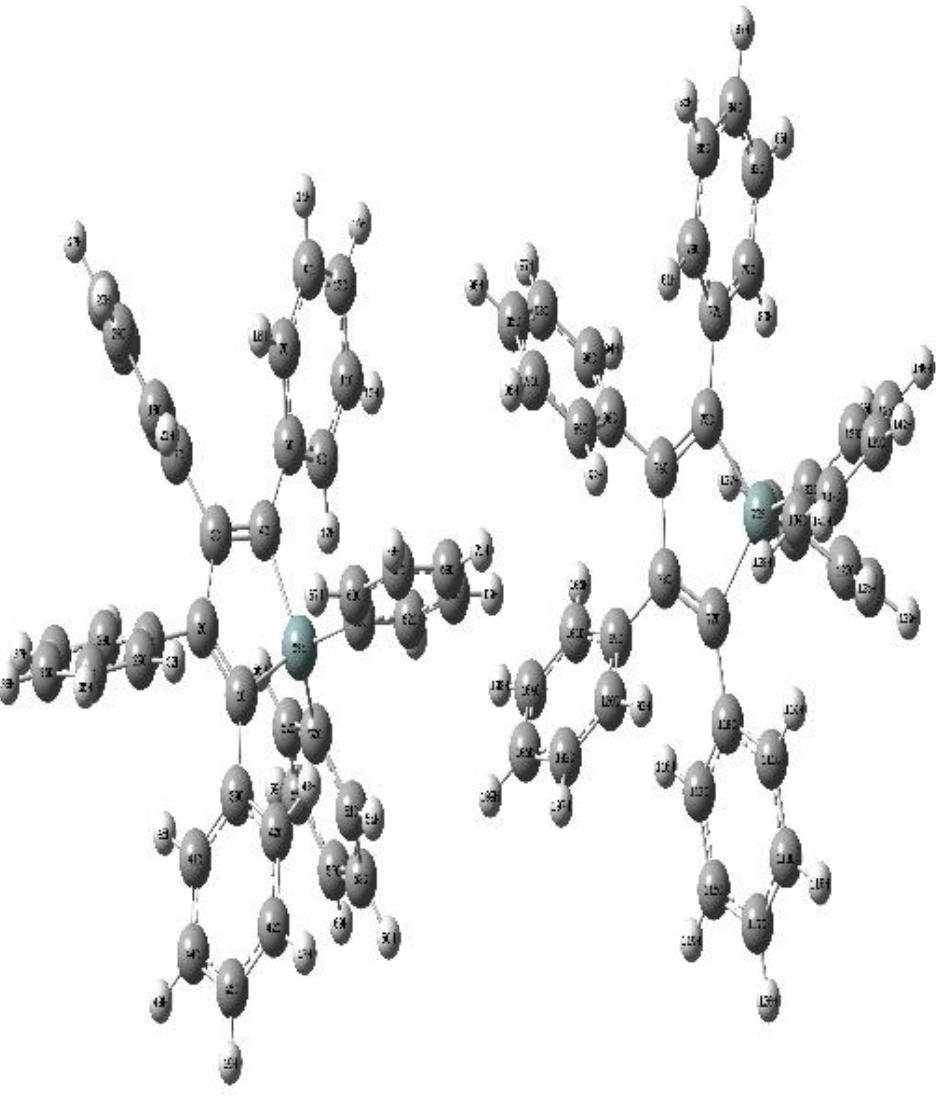

b)

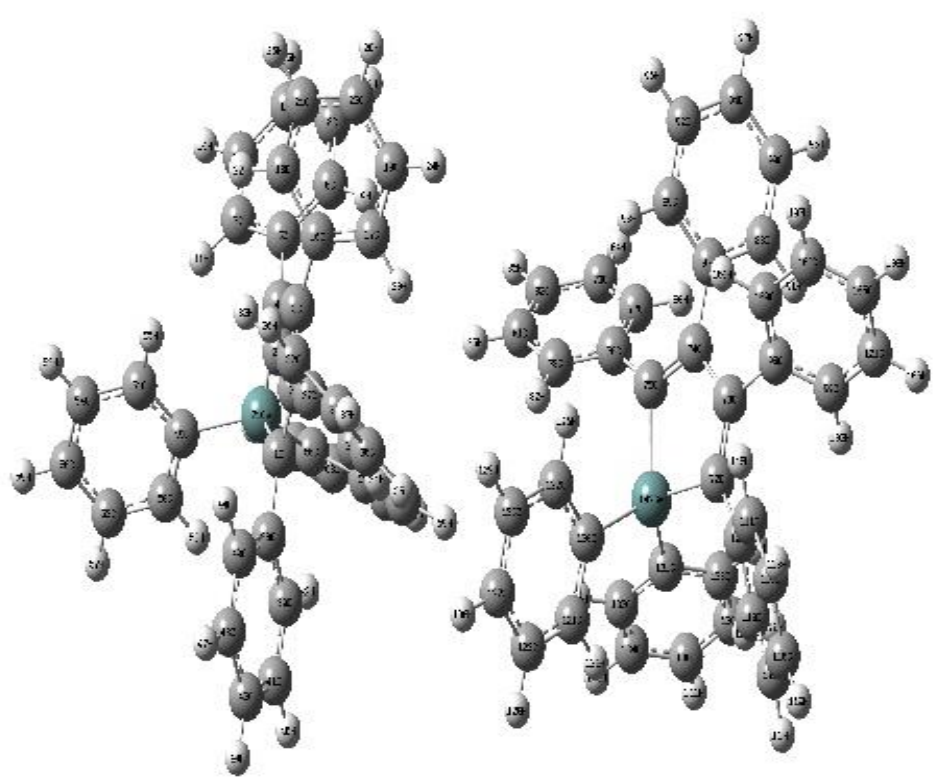

Fig. 3. Optimized structure of a) HPS dimer and b) HPG dimer. 

Figures

a)

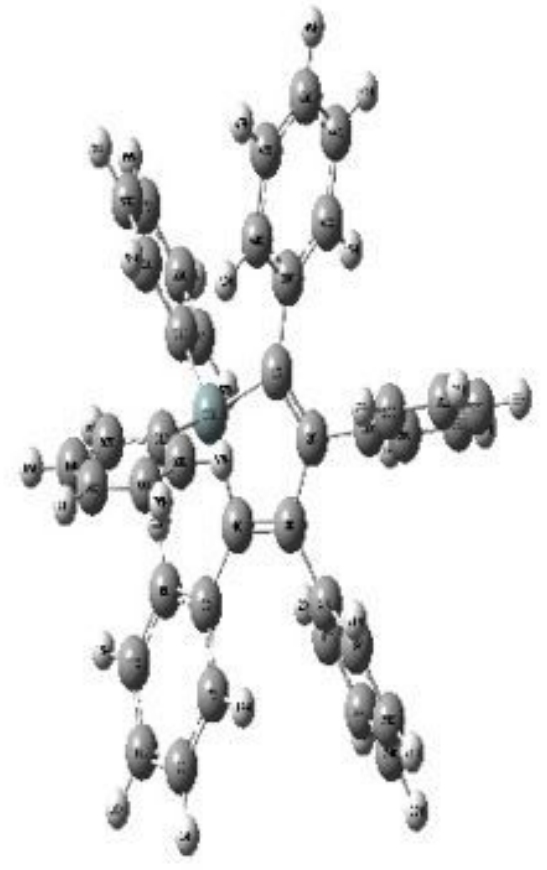

b)

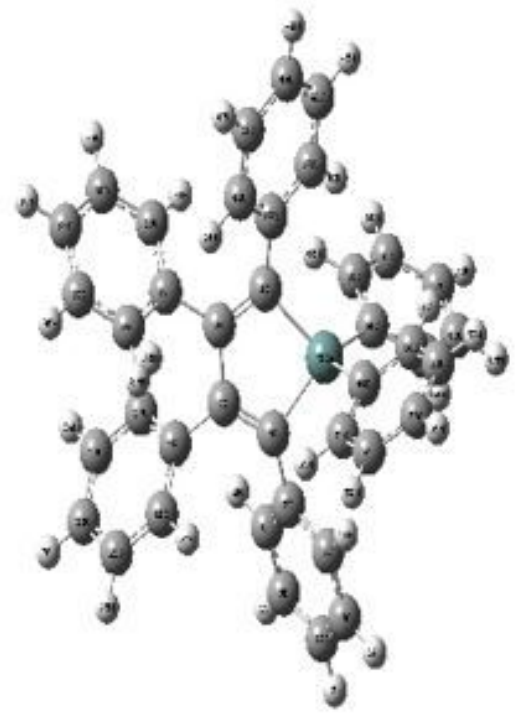

Figure 1

Optimized molecular structures of a)HPS and b)HPG. 

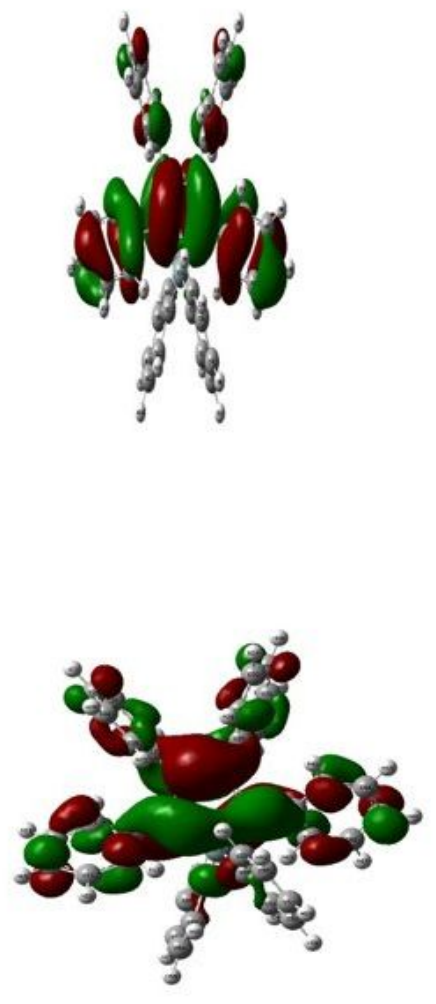
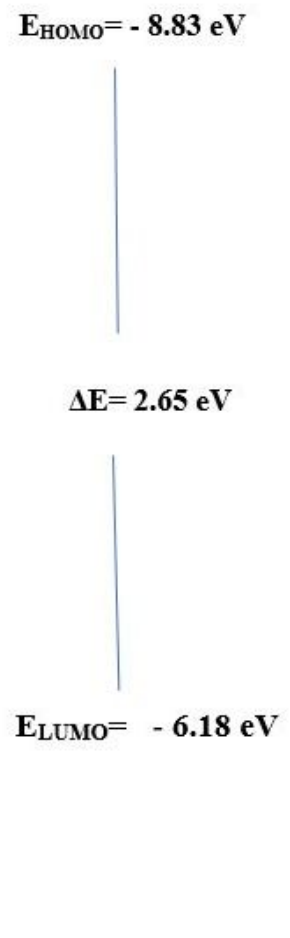
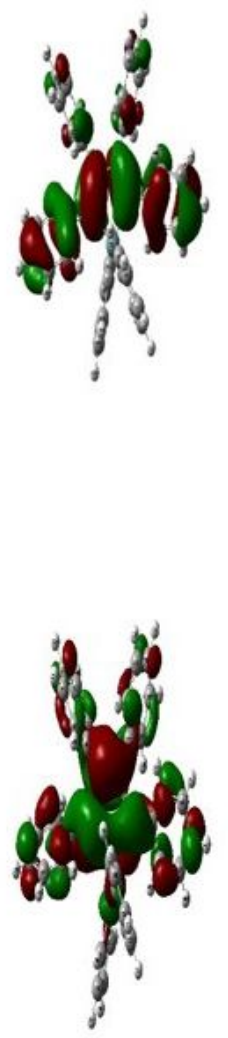

$\mathrm{E}_{\text {Hомо }}=-9.20 \mathrm{eV}$

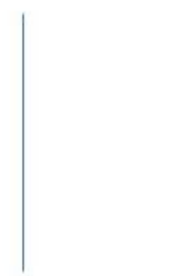

$\Delta E=2.58 \mathrm{eV}$

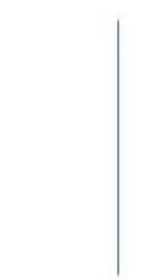

$E_{\text {LUMO }}=-6.62 \mathrm{eV}$

Figure 2

Frontier orbital contour plot a)HPS and b)HPG. 
a)

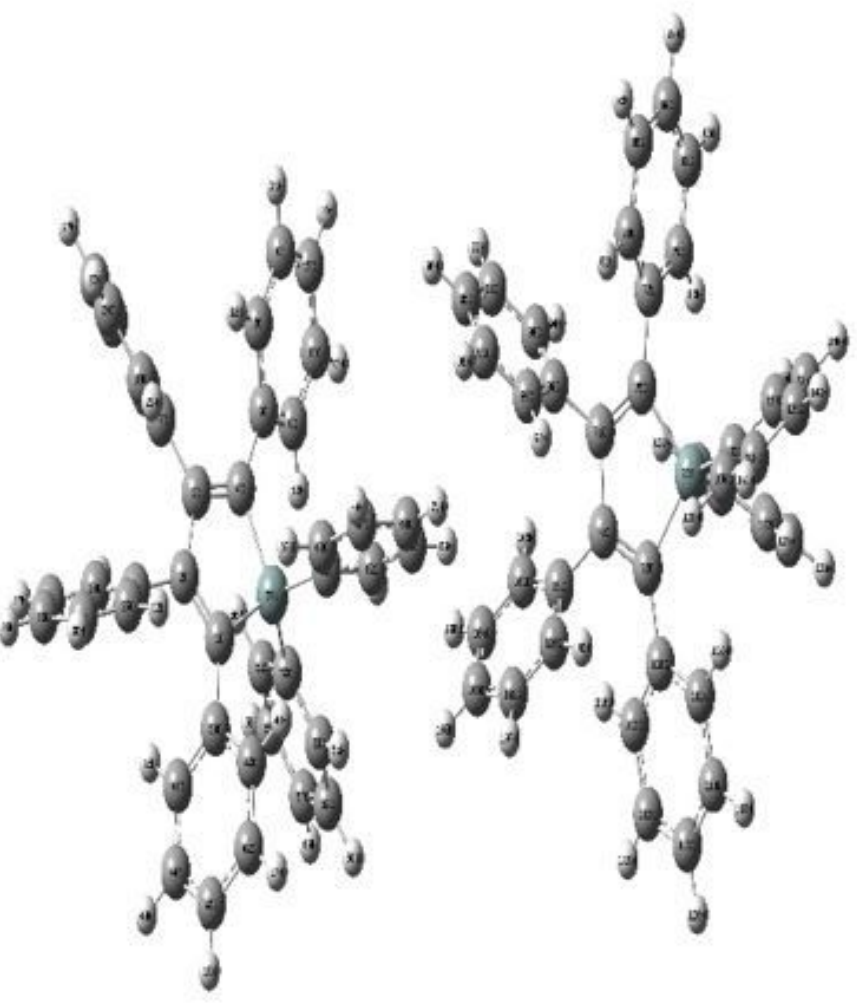

b)

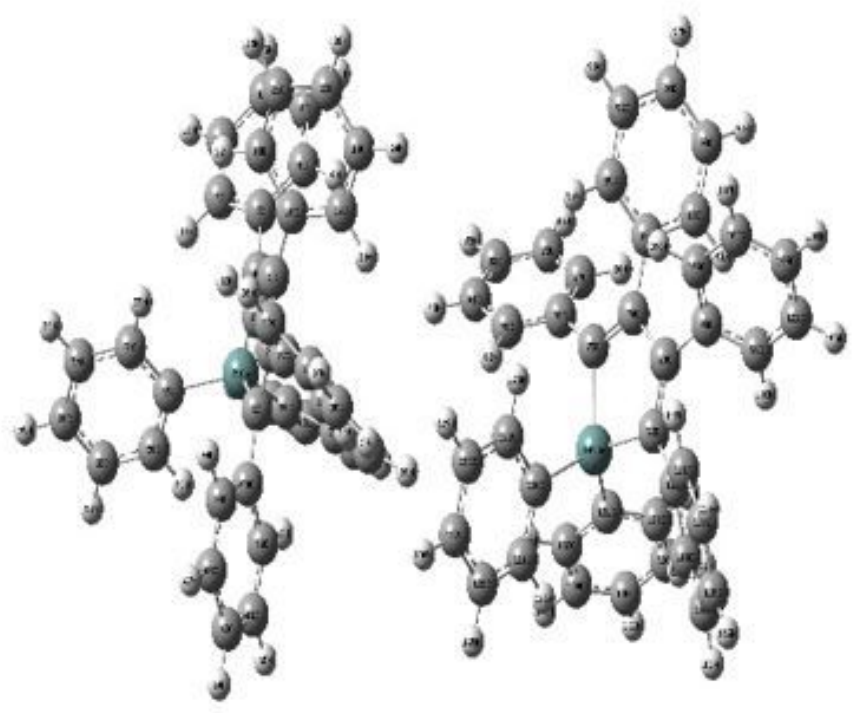

Figure 3

Optimized structure of a) HPS dimer and b) HPG dimer. 